\title{
Uima-allas tarhaminkille (Mustela vison) - hyvinvointia vai ei?
}

\author{
Hannu T. Korhonen ${ }^{1} \&$ Lauri Jauhiainen. ${ }^{2}$ \\ ${ }^{1}$ MTT, Kotieläintutkimus, Turkiseläimet,69100 Kannus (hannu.t.korhonen@mtt.fi) \\ ${ }^{2}$ MTT, Tutkimuksen tuki, 31600 Jokioinen (lauri.jauhianen@mtt.fi)
}

\section{Johdanto}

Luonnossa elävää villiä minkkiä (Mustela vison) luonnehditaan ns. semiakvaattiseksi eläimeksi. Se elää purojen, jokien, järvien ja merien rannoilla ja pyydystää niin vedestä kuin maaltakin ravintonsa. Parhaimmillaan 30-70\% minkin ravinnosta koostuu vedessä elävistä saaliseläimistä (Dunstone ja Birks, 1987). Hyvin vettä eristävää turkkia ja pieniä räpylämäisiä ihopoimuja varpaiden välissä on pidetty tyypillisinä sopeutumina vesielämään. Minkki on myös hyvä uimari (Niemimaa, 1995), sen sijaan sukellus kestää harvoin muutamia sekuntteja pidempään. Tyypillisesti minkki etsii ensin ravinnon rannalta käsin ja sukeltaa sitten pyydystääkseen saaliin.

Tarhaolosuhteissa minkillä ei ole ollut perinteisesti mahdollisuutta uimiseen eikä vedessä saalistamiseen. Tästä voidaan tehdä se johtopäätös, että tarhaminkki ei pysty käyttäytymään luonnonmukaisesti. Tähän seikkaan on viimeksi puututtu Euroopan neuvoston tuotantoeläinten suojelua koskevassa yleissopimuksessa (European Convention, 1999), jossa korostetaan, että minkkitiloja suunniteltaessa, rakennettaessa ja uudistettaessa on otettava huomioon mahdollisuus tehdä ympäristöä rikastuttavia sovellutuksia - erityisesti eläimen biologiset tarpeet huomioon ottaen. Tällöin tulee selvittää mahdollisuutta, että minkki pääsee veteen uimista ja lämmönsäätelyä varten. Tällä hetkellä ei kuitenkaan varmasti tiedetä, missä määrin uiminen ja pääsy veteen vaikuttavat tarhaminkin käyttäytymiseen ja hyvinvointiin. Lisäksi ei ole mitään varmuutta siitä, onko uiminen tarhassa syntyneelle minkille todellinen biologinen tarve vai ei. Jos se on todellinen, niin sen tyydyttämättä jättäminen voi johtaa hyvinvointiongelmiin (Mason et al. 2001).

Tämän tutkimuksen tarkoituksena oli selvittää (1) kuinka tärkeä tarve uimaan pääsy on tarhatulle minkille; ja (2) mitä vaikutuksia uimisen deprivoimisella on minkin hyvinvointiin ja käyttäytymiseen. Hypoteesina oli se, että jos uiminen on minkille todellinen tarve, niin uimisen deprivaatio johtaa lisääntyneeseen stressiin ja frustraatioon, minkä seurauksena stressihormonitaso (kortisoli, kortikosteroni) kohoaa. Deprivaation voidaan olettaa vaikuttavan haitallisesti myös eläimen käyttäytymiseen (lisääntyneet stereotypiat, raapiminen ja rauhattomuus). Kun minkeille annetaan deprivaatiojakson jälkeen mahdollisuus uida, niin voidaan olettaa niiden kiinnostuksen uimiseen olevan suuri. Tällaista patouman purkautumista kutsutaan ns. rebound efektiksi. Sen suuruus kertoo meille tarpeen tärkeydestä.

\section{Aineisto ja menetelmät}

Kuva 1. Kaavio koejärjestelystä. Pesäkopista (Nestbox) minkillä oli pääsy verkkopohjaiseen häkkiin (Wire-mesh cage), ja sieltä uimalaiturille (Jetty) ja siitä uima-altaaseen (Water pool).

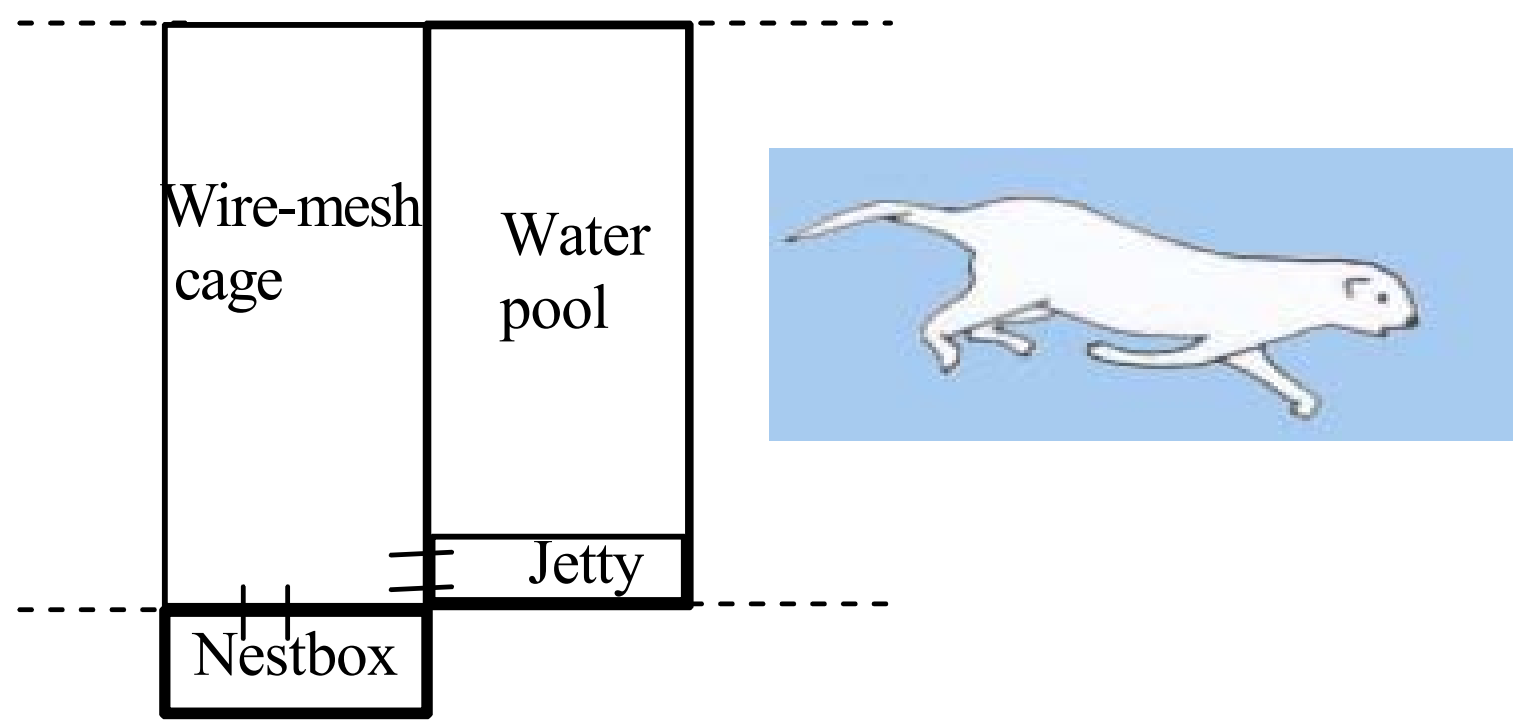


Tutkimus tehtiin Turkistalouden tutkimusasemalla (MTT) Kannuksessa v. 2000. Kokeessa oli kaksi koeryhmää: 1) deprivaation kesto 2 viikkoa; ja 2) deprivaation kesto 4 viikkoa. Koe-eläiminä olivat aikuiset standard värityypin urosminkit. Kummassakin ryhmässä oli 12 eläintä. Uima-altaat $(25 \mathrm{~cm} \mathrm{x}$ $25 \mathrm{~cm}$; pituus x leveys x korkeus; altaissa vettä 25 litraa) annettiin minkeille toukokuun puolivälissä (Kuva 1). Deprivaatio ajoittui heinä-elokuulle. Eläinten käyttäytyminen kuvattiin videokameralaitteiston avulla. Vuorokausivirtsasta määritettiin kortisoli ja kortikosteroni kuutena eri ajanjaksona. Yksityiskohtainen kuvaus menetelmistä ja tuloksista ilmenee julkaisusta Korhonen et al. (2003).

\section{Tulokset}

Minkkien uimismotivaatio oli vähäinen, sillä ne viettivät vain noin 1 min vuorokaudessa kokonaan vedessä. Minkki sen sijaan upotti päänsä altaan reunalta veteen useammin. Tällaisen ns. head dipping käyttäytymisen osuus oli 4-10 min/vrk. Uimalaiturilla minkit lisäksi leikkivät vedellä 18-27 min/ vrk.

Vähäisestä uimismotivaatiosta huolimatta deprivaatio kohotti jossain määrin sekä kortisoli- että kortikosteronitasoja. Muutos oli molemmilla ryhmillä samansuuntainen (Kuva 2). Samoin muutos oli samankaltainen niin kortisolin kuin kortikosteronin suhteen. Hormonitasojen nousu oli suurinta 2 viikkoa deprivaation jälkeen. Kun uima-altaat annettiin eläimille takaisin, hormonitasot kääntyivät lievään laskuun.

Yleisimmät käyttäytymistoiminnot ilmenevät taulukosta 1. Deprivaatio vähensi minkkien pesässä viettämää aikaa merkitsevästi ja kohotti liikunta-aktiviteettia (rauhattomuus). Deprivaatiolla ei ollut oleellista vaikutusta stereotypioiden määrään. Uimiskäyttäytymisessä (uiminen, head dipping, laiturillaoloaika) ei havaittu rebound efektiä deprivaation jälkeen.

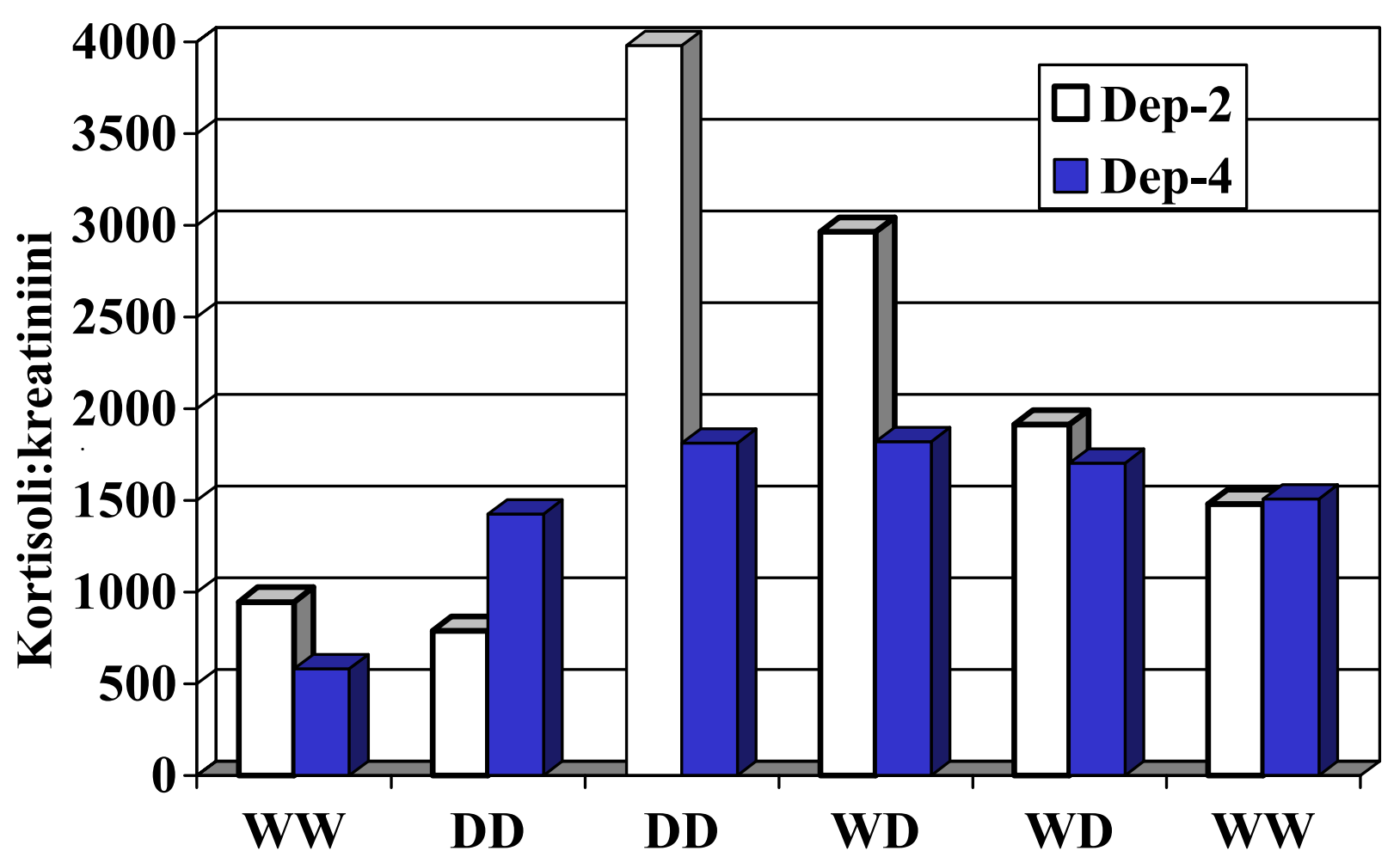

Kuva 2. Minkkien kortisoli-kreatiniini suhde vuorokausivirtsasta määritettynä. Dep-2=deprivoitu 2 viikkoa, Dep-4=deprivoitu 4 viikkoa. $\mathrm{W}=$ uima-allas, $\mathrm{D}=$ deprivaatio. $\mathrm{WW}=14.7 ., \mathrm{DD}=18.7 ., \mathrm{DD}=27.7$., $\mathrm{WD}=1.8 ., \mathrm{WD}=11.8$., $\mathrm{WW}=15.8$. Kuvio kortikosteroni-kreatiniini suhteen osalta oli samansuuntainen. Se on nähtävissä julkaisussa Korhonen et al. (2003). 
Taulukko 1. Yleisimmät käyttäytymistoiminnot (keskiarvo min/vrk, SEM).Ryhmän sisäinen vertailu: keskiarvot, joissa sama pieni kirjain eivät eroa toisistaan tilastollisesti. Ryhmien välinen vertailu (Dep2 vs Dep-4): P-arvo ilmaisee tilastollisen eron. $\mathrm{Ns}=$ ei merkitsevä ero. $\mathrm{W}=$ uima-allas, $\mathrm{D}=$ deprivaatio.

Periodi

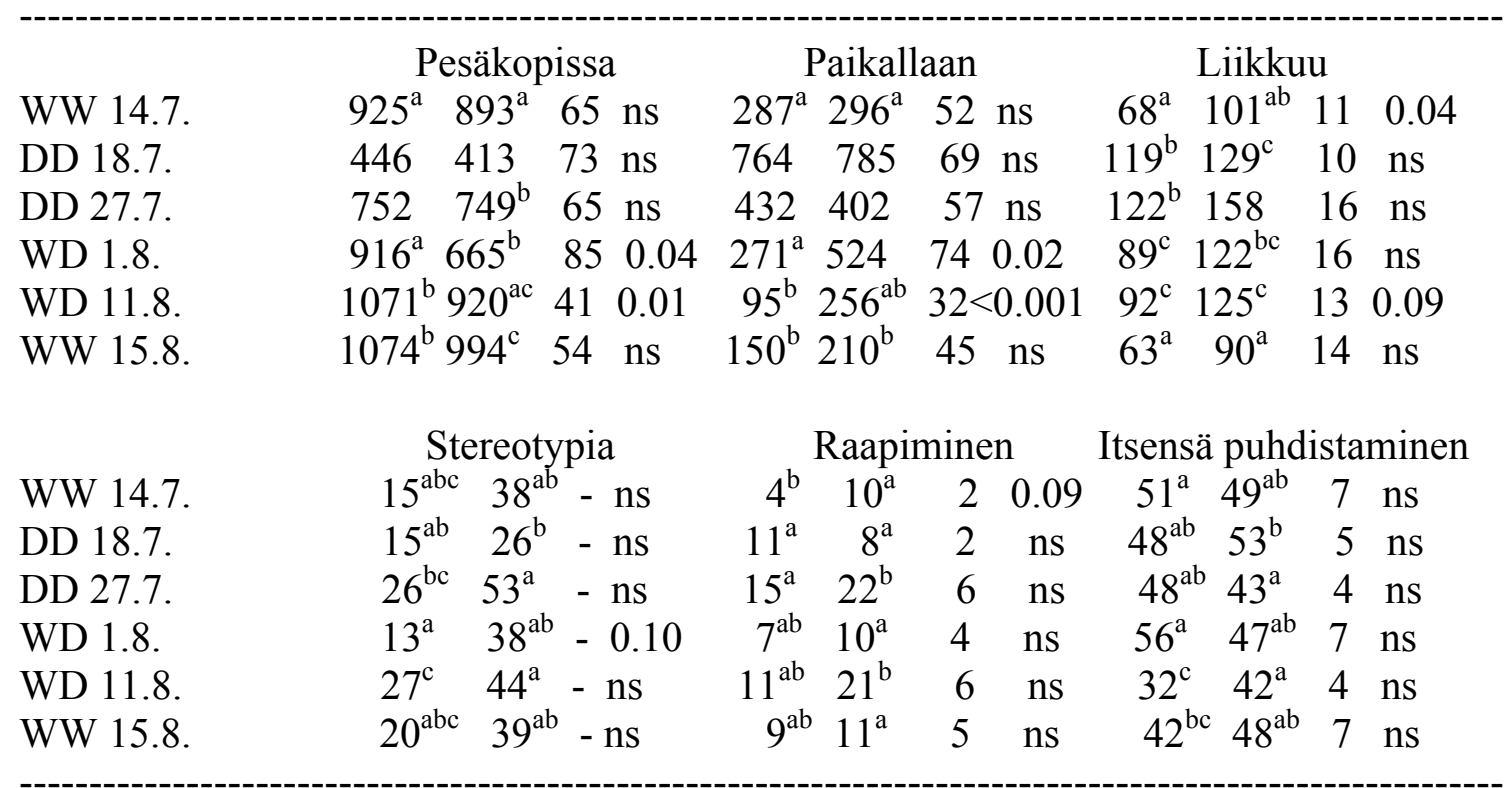

\section{Tulosten tarkastelu}

Ennen kuin mennään lähemmin tulosten tarkasteluun, on syytä korostaa, että uima-altaan tarjoaminen tarhaminkille lisävirikkeeksi ei ole mikään uusi ajatus. Jo 1930-luvulla niin Ruotsissa kuin Kanadassakin kokeiltiin niitä. Tulokset olivat osin ristiriitaisia, mutta käytännössä tilanne meni lopulta siihen, että altaista luovuttiin. Tärkeimpänä syynä oli se, että tarhaus oli huomattavasti hankalampaa silloin kun häkeissä oli allas. Tällä hetkellä kysymys uima-altaan tarpeellisuudesta on jälleen ajankohtainen. Koska 1930-luvun kokeilut olivat lähinnä käytännöllisiä - ei niinkään tieteellisiä - on asia syytä tutkia nyt perinpohjin. Tämä tutkimus on yksi niistä lukuisista, joka omalta osaltaan pyrkii löytämään vastauksen kysymykseen "tarvitseeko tarhaminkki uima-allasta vai ei?".

Minkki menee luonnossa veteen ensi sijassa pyytämään ravintoa (esim. kalaa). Saalistusstratergia on kaksivaiheinen: 1) minkki pyrkii kohdentamaan saaliin rannalta upottamalla ainoastaan päänsä veteen. 2) Kun saalis on havaittu, minkki sukeltaa sen perään. Tyypillisesti sukellus kestää vain 5-20 s. Piirteitä tästä kaksi vaiheisesta saalistusstrategiasta oli havaittavissa myös nykyisessä tutkimuksessa tarhaminkillä. Uimaveteen liittyen havaittiin sekä pään veteen kastamiskäyttäytymistä (head dipping) sekä varsinaista uimista/sukeltamista altaassa. Itse uimisen/sukeltamisen osuus oli hyvin vähäinen eli noin 1 min per vrk. Head dipping'in osuus sen sijaan oli 4-10 min/vrk. Tämä antaa viitteitä siitä, että myös tarhaminkki yritti kastamalla pään veteen etsiä saalista, mutta kun sitä ei altaassa ollut niin se ei laukaissut sukeltamis/uimistoimintoa. Lisäksi tarhalla minkit ruokitaan päivittäin runsaalla rehuannoksella häkin katolle, joten niillä ei ole nälän aiheuttamaa tarvetta etsiä ravintoa vedestä.

Laboratoriokokeissa Mason et al. (2001) havaitsivat, että uimaan tottuneet minkit stressaantuvat, jos niiden pääsy uimaveteen estetään. Heidän kokeessa stressi ilmeni kohonneina kortisoliarvoina 24 tunnin kuluessa deprivaatiosta. Mason et al. (2001) eivät rekisteröineen minkkien uimiskäyttäytymistä, joten itse uimismotivaation voimakkuudesta ei niiltä osin ole varmuutta. Heidän tutkimuksensa mukaan minkit olivat kuitenkin halukkaita tekemään työtä päästäkseen uimaveteen.Nykyisessä tutkimuksessa kortisoliarvojen (samoin kuin kortikosteronin) kohoaminen oli huomattavasti hitaampaa, sillä huippuarvot mitattiin vasta noin 2 viikkoa deprivaatiosta. Ensimmäisen 24 tunnin aikana ei ilmennyt tilastollisesti merkitsevää nousua. Samoin stressihormonitasojen palautuminen deprivaation jälkeen oli suhteellisen hidas ilmiö. On mahdollista, että vähäisen uimismotivaation vuoksi minkit eivät aluksi tiedostaneet deprivaatiota ja siksi niiden reaktio altaiden poistamiseen oli hidas. Sama saattaa selittää myös hormonitasojen hitaan muutoksen deprivaation jälkeen.

Mason et al. (2001) havaitsivat minkeillä selvää liikunta-aktiviteetin kohoamista deprivaation jälkeen. Myös nykyisessä tutkimuksessa havaittiin samansuuntaista muutosta, joka ilmeni sekä 
lisääntyneenä liikuntana että vähentyneenä aikana jonka minkki vietti pesässä. Myös raapimisen määrä lisääntyi hieman. Kaikki nämä muutokset indikoivat jonkinasteista deprivaation jälkeistä rauhattomuutta. Stereotyyppisen käyttäytymisen määrässä ei kuitenkaan havaittu mitään muutoksia. Yleensähän stereotypioita pidetään tärkeimpinä käyttäytymishäiriöiden indikaattoreina minkillä.

Kahden ja neljän viikon deprivaatio tuotti varsin samansuuntaisen tuloksen. Joten näyttää, että kaksi viikkoa on riittävä aika saamaan esiin deprivaation aiheuttamat fysiologiset ja käyttäytymismuutokset. Sen sijaan alle kahden viikon deprivaatio on ilmeisesti liian lyhyt, sillä kuten hormonimuutokset osoittivat, niin eläin ei välttämättä reagoi maksimaalisesti deprivaatioon heti vaan tietyllä viiveellä. Mason et al. (2003) tutkimuksessa käytetty yhden vuorokauden deprivaatio on mielestämme liian lyhyt luotettavien johtopäätösten tekoon.

Keskeisin kysymys kuuluu: "Parantaako uima-allas tarhaminkin hyvinvointia?". Lopullisen yksiselitteistä vastausta tähän on mahdoton vielä antaa. Uima-altaalla näyttää olevan kahdenlaisia vaikutuksia, nimittäin positiivisia ja negatiivisia. Kuten nähtiin, minkit jotka oli totutettu uimaveteen, näyttävät jossain määrin hetkellisesti "stressaantuvan" jos uimavesi poistetaan niiltä. Mutta mikä on tilanne, jos minkillä ei ole mitään aiempaa kokemusta uimavedestä?. Vinken ja Spruijtin (2001) mukaan sellaiset minkit eivät koe uimaveden puutetta mitenkään negatiivisena. Uima-altaan, niin kuin monen muunkin virikkeen kohdalla, voidaan kysyä että tarkoittaako "out of sight" myöskin "out of mind". Eli kaipaako eläin sellaista mistä sillä ei ole mitään tietoa tai aiempaa kokemusta.

Käytännössä uima-altaan antaminen minkille ympärivuotiseen käyttöön ei ole mikään yksinkertainen asia (Korhonen et al. 2003). Eräs ongelma on Suomen luonnonolosuhteet. Meillähän vesi jäätyy jo loka-marraskuussa ja sulaa vasta toukokuussa. Näinollen jos minkille annetaan uimaaltaat, ne ovat toisen puolen vuodesta jäässä. Tämä on luonnon itsensä aiheuttamaa deprivaatiota. Voidaankin kysyä, että missä määrin tarhaminkki stressaantuu, jos se kesällä oppii uimaan ja sitten talven tullen uiminen estyy?

Ongelman aiheuttaa myöskin se, että uima-altaasta tultuaan minkki kuljettaa osan vedestä turkissaan pesäkoppiin. Näin koppi kostuu eikä tarjoa etenkään kylmällä säällä riittävästi suojaa eläimelle. Minkki on adaptoitunut melko korkeaan lämpötilaan, esim. sen alempi kriittinen lämpötila on niinkin korkea kuin noin $+20{ }^{\circ} \mathrm{C}$ (Korhonen et al. 1983). Minkki pärjäänkin Suomen talvessa ainoastaan jos sillä on käytössään kuiva pesä jossa on runsaasti kuivikkeita.

Tällä hetkellä minkin uimaveden tarvetta tutkitaan intensiivisesti neljässä Euroopan maassa eli Tanskassa, Suomessa, Englannissa ja Hollannissa (Korhonen ja Niemelä, 2000). Tutkimusta rahoittaa ja koordinoi Euroopan neuvoston yhteyteen perustettu Fur Animal Welfare Research Committee (FAWRC). Tutkimukset päättyvät v.2004, jonka jälkeen voidaan luultavasti antaa lopullinen vastaus siihen, tarvitseeko tarhaminkki uima-allasta vai ei.

\section{Johtopäätökset}

Tulokset antavat viitteitä siitä, että uimisen deprivaatio saattaa jossain määrin vaikuttaa minkkiin. Vaikutus ei ollut kuitenkaan kovin dramaattinen, ja sen kesto oli lyhytaikainen. Pääosa aiemmista kokeista tukee käsitystä, että uiminen ei ole oleellinen tarve tarhatulle minkille. Tarhattu minkki syntyy häkkiympäristöön eikä sillä ole siten kokemusta vesielementistä. Voidaankin kysyä, että kaipaako minkki uimavettä jos sillä ei ole mitään tietoa tai aiempaa kokemusta siitä? Vaustauksen tähän kysymykseen tulevat antamaan laajat kokeet, joita paraikaa tehdään eri puolilla Eurooppaa Fur Animal Welfare Research Committee'n (FAWRC) koordinoimana.

\section{Kirjallisuus}

Dunstone, N. \& Birks, J.D.S. 1987. The feeding ecology of mink (Mustela vison) in coastal habitat. J. Zool. London 212: 69-83.

European Convention. 1999. Standing Committee of the European Convention for the Protection of Animals kept for Farming Purposes (T-AP). Recommendation Concerning Fur Animals. Strasbourg.

Korhonen, H., Harri, M. \& Asikainen, J. 1983. Thermoregulation of polecat and raccoon dog: a comparative study with stoat, mink and blue fox. Comp. Biochem. Physiol. 74A: 225-230.

Korhonen, H. \& Niemelä, P. 2000. Minkin uimaveden tarvetta tutkitaan. Turkistalous 72 (8-9):218-219.

Korhonen, H., Jauhiainen, L. \& Niemelä. P. 2003. Effect of swimming deprivation on adrenocortical and behavioural responses in farmed mink (Mustela vison). 3: 145-163.

Mason, G., Clareborough, C. \& Cooper, J. 2001. Frustrations of fur-farmed mink. Nature 410: 35-36.

Niemimaa, J. 1995. Activity patterns and home ranges of the American mink (Mustela vison) in the Finnish Outer Archipelago. Ann. Zool. Fenn. 32: 117-121. 